\title{
Association between the Globe Score, Uk-Score and The Response to Ursodesoxycholic Acid During Primary Biliary Cholangitis
}

\author{
Lajouad $\mathrm{S}^{1 *}$, Bouziane $\mathrm{A}^{2}$, Benelbaghdadi $\mathrm{I}^{3}$, Berhili $\mathrm{K}^{4}$, Lagdali $\mathrm{N}^{5}$, Borahma $\mathrm{M}^{6}$, Ajana $\mathrm{F}^{7}$ \\ 1,3-7 Department of Medecine C, CHU Ibn Sina University Mohamed V Rabat-Maorocco \\ ${ }^{2}$ Laboratory of Epidemiology and Clinical Research, Faculty of Dentistry Mohamed V University Rabat-Morocco
}

DOI: $10.36348 /$ sjmps.2019.v05i11.004

| Received: 21.10.2019| Accepted: 28.10.2019| Published: 09.11.2019

*Corresponding author: Sanae lajouad

\section{Abstract}

Introduction: Ursodeoxycholic acid (AUDC) is the standard treatment for primary biliary cholangitis (PBC). Prescribing it at an early stage slows the progression of the disease and improves survival. Thus, the biological response to AUDC is considered as the main predictor of survival without liver transplantation. New scores, the Globe-score, and UK-score have recently been validated as the main prognostic factor during PBC. The purpose was to study the association between the Globe-score, UK-Score and the AUDC response during PBC. Patients and Methods: This is a retrospective study of all PBC cases treated by AUDC at a dose of $13-15 \mathrm{mg} / \mathrm{kg}$ over a 22-year period (January 1998-May 2019). Treatment response was defined by the Paris II criteria at 1 year (a serum alkaline phosphatase (PAL) level 1.5 times the upper limit of normal (LSN), an aspartate aminotransferase (ASAT) level 1.5 times the LSN, normal bilirubinemia). The Globescore and UK-PBC score have been calculated for all our patients. The statistical analysis of the data was done using the SPSS software. The comparison between good treatment responders and non-responders was made using the Chi2 test for qualitative variables and the Mann-Whitney test for quantitative variables. A combination of variables was considered statistically significant if $\mathrm{p}<0.05$. Results: During the study period, 90 cases of PBC were collected. There were 85 women and 5 men. The average age was $4912.3 .52 .3 \%$ patients $(n=34)$ had a complete therapeutic response while 31 patients (47.7\%) retained non-response after one year of AUDC treatment. The average Globe score for good responders was $-0.62[-0.72 ;-0.36]$ and for non-responders was $1.53[1.32 ; 1.75]$ with a statistically significant difference (p0.001). The average UK-score value at 5 years; 10 years; 15 years for the correct answers was $1.8 \%$ [1.6-2.5]; 5.9\%[5.2-8.2]; $10.7 \%[9.5-14.8]$ and for non-responders was 9.1\%[6.7-9.9]; 27.4\%[20.4-29.5]; 44.9\%[34.6-47.8] respectively with a statistically significant difference (p0.001). Conclusion: This analysis confirms the association between the Globe-score, UK-score and the response to AUDC during primary biliary cholangitis.

Keywords: PBC, AUDC, treatment response, Paris criteria, Globe score, UK-PBC Score.

Copyright @ 2019: This is an open-access article distributed under the terms of the Creative Commons Attribution license which permits unrestricted use, distribution, and reproduction in any medium for non-commercial use (NonCommercial, or CC-BY-NC) provided the original author and source are credited.

\section{INTRODUCTION}

Primary biliary cholangitis (PBC), the new name for primary biliary cirrhosis, is a cholestatic disease of autoimmune etiology and is the leading cause of intrahepatic cholestasis. It is characterized by the destruction of small bile ducts due to lymphocytic infiltration. The prevalence of $\mathrm{PBC}$ is 10 to 40 per 100,000 population. $\mathrm{PBC}$ preferentially affects women (90\% of the time) with a median age of 55 years at diagnosis. Thus, among women over 40 years of age, the prevalence of $\mathrm{PBC}$ is 1 per $1000[1]$.

Ursodeoxycholic acid (AUDC) is currently the standard treatment for primary biliary cholangitis (PBC). Prescribing it at an early stage slows the progression of the disease and improves survival. Thus, the biological response to AUDC is considered as the main predictor of survival without liver transplantation. New scores, the Globe-score, and UK-score have recently been validated as the main prognostic factor during PBC. The purpose was to study the association between the Globe-score, UK-Score and the AUDC response during $\mathrm{PBC}$.

\section{PATIENTS AND METHODS}

This is a retrospective study collecting all cases of PBC followed in the Department of Medicine $\mathrm{C}$ at the University Hospital Ibn Sina Mohamed V University of Rabat, treated by AUDC at a dose of 13$15 \mathrm{mg} / \mathrm{kg}$, over a period of 22 years (January 1998September 2019). 
The diagnosis of $\mathrm{PBC}$ was made on: the presence of biological cholestasis (alkaline phosphatases (PAL) > 1.5 times the upper limit of normal (LSN) and/or Gamma glutamil transferase GGT>3 times LSN) associated with one of the following criteria:

- Anti-mitochondria antibody type M2 positive $(>1 / 40)$

- AAN's sub AC: gp210 or sp100 positive

- Histological sign of PBC on liver biopsy puncture biopsy

Treatment response was defined by the Paris II criteria at 1 year (a serum alkaline phosphatase (PAL) level 1.5 times the upper limit of normal (LSN), an amino transferase aspartate (ASAT) level 1.5 times the LSN, normal bilirubinemia). The Globe-score and UKPBC score have been calculated for all our patients.

\section{STATISTICAL ANALYSIS}

The statistical analysis of the data was done using the SPSS software.

The comparison between good treatment responders and non-responders was made using the Chi2 test for qualitative variables and the MannWhitney test for quantitative variables.

A Spearman correlation was sought between the Globe- score and the UK-PBC score.

A combination of variables was considered statistically significant if $\mathrm{p}<0.05$.

\section{RESULTS}

Over the period from January 1998 to September 2019, ninety patients with PBC were collected in our study.

The average age (years) was 49 12.3.

In our series, we note a clear female predominance; it was 85 women $(94.4 \%)$ and 5 men $(5.6 \%)$ with a sex ratio M/F: 0.06 .

In our series, 12 cases are newly diagnosed, and 13 patients were lost to follow-up before 1 year of progression on AUDC. The evaluation of the response to AUDC after 1 year according to the Paris II criteria could therefore only be assessed in 65 patients.

$52.3 \%$ patients $(\mathrm{n}=34)$ had a complete therapeutic response while non-response was retained in 31 patients $(47.7 \%)$ after one year of AUDC treatment.

\section{Factors associated with therapeutic non-response were (Table 1)}

- The presence of jaundice with a statistically significant difference $(\mathrm{p}=0.02)$
- The presence of clinically significant PHT signs with a statistically significant difference $(p=0.04)$

- Low TP with a statistically significant difference ( $\mathrm{p}$ 0.001 )

- The presence of OV with a statistically significant difference (p 0.001)

- The presence of VSCs with a statistically significant difference $(\mathrm{p}=0.02)$

- Hypertensive gastropathy at endoscopy with a statistically significant difference $(\mathrm{p}=0.002)$

- The presence of ductopenia, extensive septal fibrosis and cirrhosis (Scheuer stages II, III, and IV) at liver biopsy puncture with a statistically significant difference $(\mathrm{p}=0.01)$.

Table-1: Factors influencing the response to AUDC

\begin{tabular}{|l|l|}
\hline Variables & P value \\
\hline Ictera & $p=0,02$ \\
\hline HTP Clinical Signs & $p=0,04$ \\
\hline Biology & \\
Low TP $(<70 \%)$ & $p<0,001$ \\
\hline Endoscopy & $p<0,001$ \\
VO & $p=0,02$ \\
VSC & $p=0,002$ \\
HTP Gastropathy & \\
\hline Histology & $p=0,01$ \\
Ductopenia & $p=0,01$ \\
Extensive septal fibrosis & $p=0,01$ \\
Cirrhosis &
\end{tabular}

The response to AUDC was obtained in $52.3 \%$. Factors associated with therapeutic nonresponse were the presence of clinical and endoscopic HTP jaundice, low PT, cirrhosis, and/or ductopenia.

The Globe-score and UK-PBC score were calculated in 65 patients because in our series, 12 cases are newly diagnosed, and 13 patients were lost to follow-up before 1 year of disease progression.

The median survival value according to the Globe score:

Among the good answerers

- $\quad$ at 5 years old was $96.6 \%[93.8$ - 96.7];

- $\quad$ at 10 years old was $91.2 \%$ [84.2- 91.5]; and

- at 15 years of age was $84.8 \%[73.5-85.2]$ and

For non-responders

- $\quad$ at 5 years was $75.7 \%[69.7-78.9]$;

- at 10 years old was $46 \%[37.5-52.8]$ and

- at 15 years of age was $24.4 \%[15.3-31.8]$.

In our series $63 \%$ patients had a life expectancy similar to that of the general population matched by age and sex i.e. a Globe score $\leq 0.30$, and $37 \%$ had a life expectancy significantly lower than that of the general population similar to the age and sex Globe score $>0.3$. 
The average Globe score for good responders was $-0.62[-0.72 ;-0.36]$ and for non-responders was

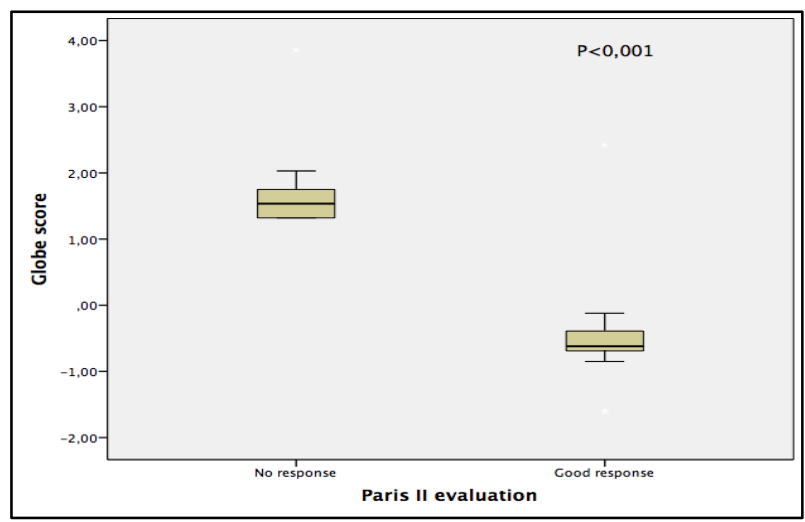

Fig-1

The median value of UK-score

Among the good answerers

- at 5years $1.8 \%[1.6-2.5]$

- 10 years $5.9 \%[5.2-8.2]$

- 15 years $10.7 \%[9.5-14.8]$

\section{For non-responders}

- 5 years $19.1 \%[6.7-9.9]$

- 10 years $5.9 \% 27.4 \%$ [20.4-29.5]

- $15 y e a r s ~ 10.7 \% 44.9 \%[34.6-47.8]$.

The difference between good responders and non-responders according to UK-PBC Score was statistically significant (p0.001) (Figures 2-3).
$1.53[1.32 ; 1.75]$ with a statistically significant difference (p0.001) (Table 2, Figure 1).

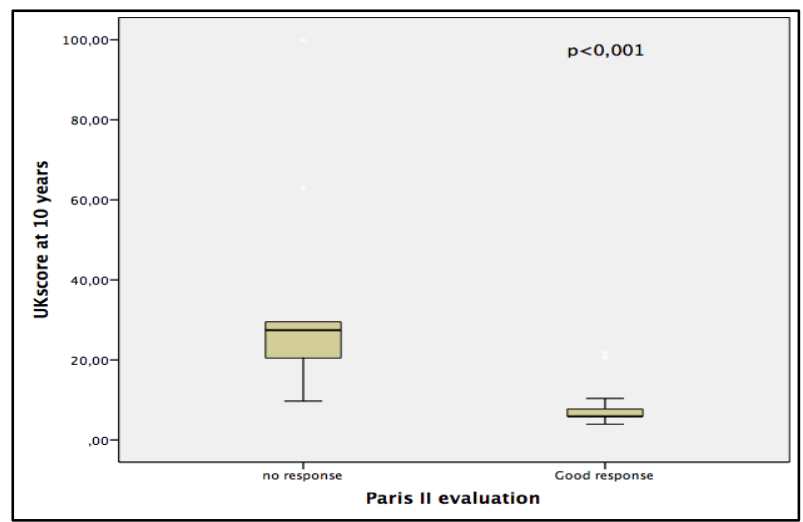

Fig-2

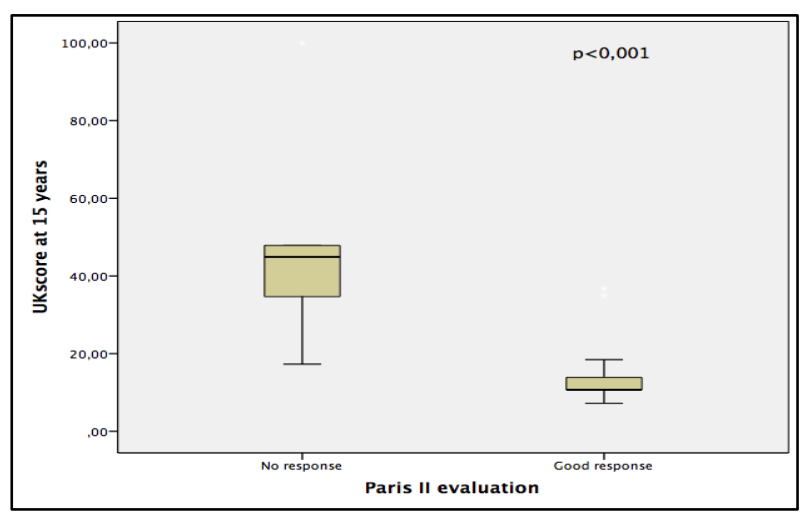

Fig-3

Table -2: Globe Score, UK-PBC score and the Reponse to AUDC

\begin{tabular}{|l|l|l|l|}
\hline & $\begin{array}{l}\text { Non responder } \\
(\mathbf{n = 3 1})\end{array}$ & $\begin{array}{l}\text { Good responder } \\
(\mathbf{n = 3 4 )}\end{array}$ & P value \\
\hline Globe score & $1,53[1,32 ; 1,75]$ & $-0,62[-0,72 ;-0,36]$ & $\mathrm{p}<0,001$ \\
\hline UK-PBC to 5 years & $9,1 \%[6,7-9,9]$ & $1,8 \%[1,6-2,5]$ & $\mathrm{p}<0,001$ \\
\hline UK-PBC to 10 years & $27,4 \%[20,4-29,5]$ & $5,9 \%[5,2-8,2]$ & $\mathrm{p}<0,001$ \\
\hline UK-PBC to 15 years & $44,9 \%[34,6-47,8]$ & $10,7 \%[9,5-14,8]$ & $\mathrm{p}<0,001$ \\
\hline
\end{tabular}

The correlation between the Globe- score and the UK-PBC score for good treatment responders and non-responders was statistically significant with a $\mathrm{p}<$ 0.001 (Table 5).

Our study confirms the correlation between the Globe-score, and UK-score, hence the possibility of using a single score for survival assessment and confirms the association between the Globe-score, UKscore and AUDC response during primary biliary cholangitis.

\section{DISCUSSION}

Ursodeoxycholic acid (AUDC) is the standard treatment for primary biliary cholangitis (PBC). Prescribing it at an early stage slows the progression of the disease and improves survival. Thus, the biological response to AUDC is considered as the main predictor of survival without liver transplantation.

The biochemical response should be evaluated after one year of treatment by AUDC using one of the many published criteria listed in Table 3. [2-6]. 
Table-3: Evaluation of the biochemical response

\begin{tabular}{|ll|}
\hline Classement par an & Critères de réponse \\
\hline Rochester I & PAL 2LSN \\
Barcelona & Réduction de PAL de plus de $40 \%$ ou \\
& normalisation de PAL \\
Paris I & PAL $3 *$ LSN; ASAT 28LSN et BT: 1mg/dl \\
Rotterdam & BT< $1 *$ LSN et Albumine $>1 *$ LIN \\
Toronto & PAL $1,67^{*}$ LSN \\
Paris II & PAL $1,5{ }^{*}$ LSN; ASAT $1,5 * L S N ;$ et BT: \\
& normale \\
Rochester II & PAL $2 *$ LSN \\
Global & PAL $2 * L S N$ \\
\hline LSN: limite supérieure à la normale, LIN: limite inferieure à la normale; BT: bilirubine \\
total
\end{tabular}

In our series, the evaluation of response to treatment was defined by the Paris II criteria.

According to Kuiper EM et al. $40 \%$ of patients with $\mathrm{PBC}$ will have an inadequate response to treatment [7], in our series, $52.3 \%$ patients had a complete therapeutic response while non-response was retained in $47.7 \%$ patients after one year of AUDC treatment our results were comparable with those in the literature.

Patients whose treatment is initiated in the early stages (I and II) of the disease have survival rates similar to those of the matched group based on age and gender in the general population. [8,9]. An inadequate response to UDCA identifies patients at higher risk of rapid disease progression [10,11]. Male sex and young age at presentation are predictive factors for nonresponse to the UDCA [12]. A large cohort study by Lammers et al $(\mathrm{N}=4,845)$ provided evidence that suboptimal response is a powerful prognostic predictor for HCC development[13]. There are several definitions of the optimal biochemical response to treatment (Tables 3). These criteria can be useful tools for risk stratification in PBC[14]. They are simple to use, easily reproducible and non-invasive. The Paris-I criteria provide a significant prognostic value for survival without transplantation in the advanced stage of the disease (III and IV) and have been validated by large studies. 15, 16, 17] The Paris-I criteria should not be used for risk stratification at the beginning of PBC[18].

Corpechot et al. refined their Paris-I criteria for specific use at the beginning of PBC and developed the Paris-II criteria. In order to improve the validity of risk stratification at the beginning of $\mathrm{PBC}$, they incorporated all clinical or histological signs of cirrhosis, as well as survival without transplantation, into their study. This better reflects the evolution of the disease at the beginning of PBC. Today, most patients are diagnosed and treated in the early stages of the disease (I and II) and non-leiver-related deaths account for up to half of all deaths[19]. No evidence of disease progression could be observed over a 7-year period in patients with histologically verified early PBC (I and II) who met the Paris-II criteria[17].

In the series of Corpechot et al. it is noted that the factors influencing the response to AUDC are (Table 4): hyperbilirubinemia (>1mg/dl); albuminemia $<38 \mathrm{~g} / \mathrm{l}, \mathrm{TP}<80 \%$, the presence of anti gp210 and sp100 CA, Scheuer stage 2 and 3, moderate interface hepatitis, the presence of Ductopenia at PBF:

Table-4: Factors influencing the response to AUDC according to Corpechot and al:

\begin{tabular}{|c|c|c|}
\hline Variable & $\boldsymbol{P}$ & $\begin{array}{l}\text { Relative Risk } \\
\text { (95\% C1) }\end{array}$ \\
\hline Age $>55$ years $*$ & 0.0161 & $1.3(1.0-1.6)$ \\
\hline Total serum bilirubin $>1 \mathrm{mg} / \mathrm{dL}^{*}$ & $<0.0001$ & $2.7(2.0-3.7)$ \\
\hline$A L P>3 U L N^{*}$ & 0.0039 & $1.6(1.2-2.0)$ \\
\hline AST $>2 U^{*} N^{*}$ & 0.0138 & $1.6(1.3-2.1)$ \\
\hline Serum albumin $<38 \mathrm{~g} / \mathrm{L}^{*}$ & $<0.0001$ & $2.0(1.6-2.7)$ \\
\hline Prothrombin index $<80 \% *$ & $<0.0001$ & $2.2(1.7-2.9)$ \\
\hline Mayo score >4.5* & $<0.0001$ & $2.5(1.8-3.7)$ \\
\hline Anti-gp2 10/Sp100 antibodies* & 0.0401 & $1.5(1.0-2.1)$ \\
\hline Histological stage 3-4* & $<0.0001$ & $2.5(1.9-3.2)$ \\
\hline Moderate to severe interface hepatitis* & $<0.0001$ & $2.0(1.5-2.7)$ \\
\hline Ductopenia* & 0.0126 & $1.8(1.3-2.7)$ \\
\hline $\begin{array}{l}\text { Absence of biochemical response at } 1 \text { year } \\
\text { according to the Barcelona criteria }\end{array}$ & 0.0015 & $1.5(1.2-2.0)$ \\
\hline $\begin{array}{l}\text { Absence of biochemical response at } 1 \text { year } \\
\text { according to the present study's criteriat }\end{array}$ & $<0.0001$ & $2.9(2.1-4.2)$ \\
\hline $\begin{array}{l}\text { *At the onset of treatment. } \dagger \text { Total serum t } \\
\text { or AST }>2 \text { ULN. }\end{array}$ & $n>1 \mathrm{mg}$ & ALP $>3$ ULN, \\
\hline
\end{tabular}


In our series, the AUDC response was obtained for $52.3 \%$. Factors associated with therapeutic non-response were the presence of clinical and endoscopic HTP jaundice, low PT, cirrhosis, and/or ductopenia (Table 5).

Table 5: Factors influencing the response to AUDC

\begin{tabular}{|l|l|}
\hline Variables & P value \\
\hline Icteria & $p=0,02$ \\
\hline HTP Clinical signes & $p=0,04$ \\
\hline Biology & \\
Low TP $(<70 \%)$ & $p<0,001$ \\
\hline Endoscopy & \\
VO & $p<0,001$ \\
VSC & $p=0,02$ \\
HTP Gastropathy & $p=0,002$ \\
\hline Histology & \\
Ductopenia & $p=0,01$ \\
Extensive septal fibrosis & $p=0,01$ \\
Cirrhosis & $p=0,01$ \\
\hline
\end{tabular}

In primary biliary cholangitis (PBC), the progression of liver disease is highly variable [20, 21]. In many cases, the disease is detected at an early stage and treatment with ursodeoxycholic acid (AUDC) improves biochemistry, prevents liver fibrosis and normal life expectancy [22-23]. However, in a substantial proportion of patients, AUDC treatment is inadequate. These patients have active liver disease that may eventually lead to liver failure or hepatocellular carcinoma [24]. Several definitions of the AUDC response have been proposed [25-26]. These definitions of response to AUDC, such as the Toronto, Paris, Rotterdam and Barcelona criteria, have two major limitations: first, they dichotomize the response to AUDC and, therefore, the long-term risk of death or liver transplantation $(\mathrm{TH})$ when both are, in reality, a continuum; second, they do not take into account the stage of the disease. Two independent research groups, the Global PBC Study Group and the United Kingdom (UK) -PBC Consortium, have developed and externally validated continuous prognostic models (GLOBE score and UK-PBC risk score) that address these limitations $[27,28]$. These models include liver biochemistry after AUDC treatment as well as disease stage substitution measures (e. g. serum albumin and platelet count). They estimate the risk of $\mathrm{TH}$ or death (overall death for the GLOBE score and liver-related death for the UK-PBC risk score) in patients with $\mathrm{PBC}$ at specific times. Both scores exceeded previous response criteria [25-28] in terms of prognostic utility and could potentially help physicians identify patients at high risk of disease progression and requiring second-line treatment. They have also been validated in patients not treated with AUDC, strongly suggesting that these scoring systems reflect the disease activity and stage expressed by laboratory tests, regardless of the treatment. The recently published guidelines of the European Association for the Study of the Liver propose these criteria as tools for selecting patients for second-line treatment and possibly better design of clinical trials in PBC [29].

Answering machines according to the Globe score, are defined as patients with a GLOBE score $\leq$ 0.30 , show a life expectancy similar to that of the general population matched by age and sex. Nonresponders (GLOBE score> 0.3) had a significantly lower life expectancy than the general population similar to age and sex.

In our series $63 \%$ patients had a life expectancy similar to that of the general population matched by age and sex i.e. a Globe score $\leq 0.30$, and $37 \%$ had a life expectancy significantly lower than that of the general population similar to age and sex Globe score $>0.3$

In our series the average Globe score for good responders was $-0.62[-0.72 ;-0.36]$ and for nonresponders was $1.53[1.32 ; 1.75]$ with a statistically significant difference (p0.001).

Respondents were significantly more likely to be in the early stages of the disease (I and II) than nonrespondents [30]. The GLOBE score has a higher prognostic value than other response criteria such as the Paris-I and Paris-II criteria. It is important to note that the GLOBE score accurately stratifies risk at both the early (I and II) and late (III and IV) stages. Respondents $(\leq 0.30)$ have a low risk of future adverse events and may be advised for monotherapy with AUDC. The GLOBE score also provides a better positive predictive value of adverse events compared to other response criteria and better identification of patients requiring additional treatment or candidates for clinical trials [30].

\section{Risk Score UK-PBC}

To date, more than 6,000 liver transplants have been performed in the United States and Europe for PBC [31]. The number of liver transplants for PBC has decreased over the past two decades [17]. PBC accounts for $9 \%$ of liver transplants performed in Europe [32]. Liver transplantation is the only curative treatment for PBC [33]. This improves survival. Post-transplant survival rates are shown in Table 6.

Table-6: Survival rates after transplantation in PBC[32]

\begin{tabular}{|l|l|}
\hline Survival To 1 years & $86 \%$ \\
\hline Survival To 5 years & $80 \%$ \\
\hline Survival To 10 years & $72 \%$ \\
\hline
\end{tabular}

The UK-PBC score estimates the risk (expressed as a percentage) that a PBC patient treated with ursodeoxycholic acid (AUDC) will develop liver 
failure requiring liver transplantation within 5,10 or 15 years of diagnosis.

The score can be used to identify high-risk patients for closer monitoring and second-line therapies, as well as low-risk patients who could potentially be followed up in primary care.

In our series the median value of UK-PBC is the risk of liver transplantation and death events in good responders of up to: $1.8 \%[1.6-2.5]$ at 5 years; $5.9 \%[5.2-$ $8.2]$ at 10 years; and $10.7 \%[9.5-14.8]$ at 15 years, and among non-responders: 5 years $19.1 \%[6.7-9.9] ; 10$ years $5.9 \% \quad 27.4 \%[20.4-29.5] \quad ; \quad 15$ years $10.7 \%$ $44.9 \%[34.6-47.8]$.

\section{CONCLUSION}

Response to treatment was defined by the Paris II criteria at 1 year. The AUDC response was obtained in 52.3\%. Factors associated with therapeutic nonresponse were the presence of clinical and endoscopic HTP jaundice, low PT, cirrhosis, and/or ductopenia.

The Globe-score and UK-PBC score have been calculated for all our patients. $63 \%$ patients had a life expectancy similar to that of the general population matched by age and sex either a Globe score $\leq 0.30$, the median value of UK-PBC or the risk of liver transplantation and death event among good responders being up to: $1.8 \%[1.6-2.5]$ at 5 years; $5.9 \%[5.2-8.2]$ at 10 years; and $10.7 \%[9.5-14.8]$ at 15 years.

This analysis confirms the association between the Globe-score, UK-score and the response to AUDC during primary biliary cholangitis.

\section{REFERENCES}

1. Poupon, R. (1991). La cirrhose biliaire primitive. Schweizerische Medizinische Wochenschrift, 121(20), 727-732.

2. Lammers, W.J., Van, Buuren, H.R., Hirschfield, G.M., Janssen, H.L, Invernizzi, P., Mason, A.L. (2014). Levels of alkaline phosphatase and bilirubin are surrogate end points of outcomes of patients with primary biliary cirrhosis: an international follow-up study. Gastroenterology, 147:1338-1349 e5; quiz e15.

3. Pares, A., Caballeria, L., Rodes, J. (2006). Excellentlong-termsurvivalin patients with primary biliary cirrhosis and biochemical response to ursodeoxycholic Acid. Gastroenterology, 130:715720.

4. Momah, N., Silveira, M.G., Jorgensen, R., Sinakos, E., Lindor, K.D.(2012). Optimizing biochemical markers as endpoints for clinical tri- als in primary biliary cirrhosis. Liver Int, 32:790-795. is.

5. Corpechot, C., Abenavoli, L., Rabahi, N., Chretien, Y., Andreani, T., Johanet, C. (2008). Biochemical response to ursodeoxycho- lic acid and long-term prognosis in primary biliary cirrhosis. Hepatology, 48:871-877.

6. Corpechot, C., Chazouilleres, O., Poupon, R. (2011). Early primary bil- iary cirrhosis: biochemical response to treatment and predic- tion of long-term outcome. J Hepatol, 55:1361-1367. is șep.

7. Kuiper, E.M., Hansen, B.E., De Vries ,R.A., Den Ouden-Muller, J.W., Van, Ditzhuijsen, T.J., Haagsma, E.B. (2009). Improved prog- nosis of patients with primary biliary cirrhosis that have a bio- chemical response to ursodeoxycholic acid. Gastroenterology, 136:1281-1287.

8. Corpechot, C., Carrat, F., Bahr, A., Chrétien, Y., Poupon, R-E., Poupon, R.(2005). The effect of ursodeoxycholic acid therapy on the natural course of primary biliary cirrhosis. Gastroenterology, 128(2), 297-303. is [Lep]

9. Poupon, R. E., Lindor, K. D., Cauch-Dudek, K. A. R. E. N., Dickson, E. R., Poupon, R., \& Heathcote, E. J. (1997). Combined analysis of randomized controlled trials of ursodeoxycholic acid in primary biliary cirrhosis. Gastroenterology, 113(3), 884 890.

10. Parés, A., Caballería, L., \& Rodés, J. (2006). Excellent long-term survival in patients with primary biliary cirrhosis and biochemical response to ursodeoxycholic acid. Gastroenterology, 130(3), 715-720.

11. Bowlus, C. L., \& Gershwin, M. E. (2014). The diagnosis of primary biliary cirrhosis. Autoimmunity reviews, 13(4-5), 441-444.

12. Carbone, M., Mells, G. F., Pells, G., Dawwas, M. F., Newton, J. L., Heneghan, M. A., ... \& Alexander, G. J. (2013). Sex and age are determinants of the clinical phenotype of primary biliary cirrhosis and response to ursodeoxycholic acid. Gastroenterology, 144(3), 560-569.

13. Trivedi, P., Lammers, W., Van, Buuren, H., Janssen, H., Invernizzi, P., Battezzati, P. (2014). OC-030 Effective Stratification of Hepatocellular Carcinoma Risk in Primary Biliary Cirrhosis: Results of a Multi-centre International Study. GUT,

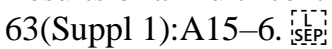

14. Lammers, W.J., Kowdley, K.V., Van, Buuren, H.R.(2014). Predicting outcome in primary biliary cirrhosis. ANN HEPATOL, 13(4):316-26. SLEP

15. Crowe, J.P., Christensen, E., Butler, J., Wheeler, P., Doniach, D., Keenan. J. (1980). Primary biliary cirrhosis: the prevalence of hypothyroidism and its relationship to thyroid autoantibodies and sicca syndrome. GASTROENTEROLOGY, 78(6):1437-

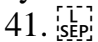

16. Dickson, E.R., Grambsch, P.M., Fleming, T.R., Fisher, L.D., Langworthy, A. (1989). Prognosis in primary biliary cirrhosis: model for decision making. HEPATOLOGY, 10(1):1-7. [i ș-pi

17. Corpechot, C., Chazouillères, O., Poupon, R. (2011). Early primary biliary cirrhosis: biochemical response to treatment and prediction of long-term 


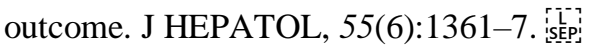

18. Papastergiou, V., Tsochatzis, E.A., RodriquezPeralvarez, M., Thalassinos, E., Pieri, G., Manousou, P. (2013). Biochemical criteria at 1 year are not robust indicators of response to ursodeoxycholic acid in early primary biliary cirrhosis: Results from a 29-year cohort study. Aliment pharmacol ther, 38(11- 12):1354-64. is.p.

19. Jones, D.E., Al-Rifai, A., Frith, J., Patanwala, I., Newton, J.L.(2010). The independent effects of fatigue and UDCA therapy on mortality in primary biliary cirrhosis: results of a 9 year follow-up. J

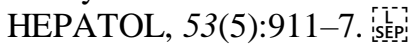

20. Lammers, W.J., van, Buuren, H.R., Hirschfield, G.M., Janssen, H.L., Invernizzi, P., Mason, A.L.(2014). Global PBC Study Group. Lev- els of alkaline phosphatase and bilirubin are surrogate end points of outcomes of patients with primary biliary cirrhosis: an interna- tional follow-up study.

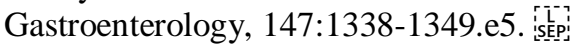

21. Carbone, M., Mells, G., Pells, G., Dawwas, M.F., Newton, J.L., Heneghan M. (2013). Sex and age are determinants of the clinical phenotype of primary biliary cirrhosis and response to ursodeoxy- cholic acid. Gastroenterology, 144:560569.e.7.

22. Poupon, R.E., Lindor, K.D., Cauch-Dudek, K., Dickson, E.R., Poupon, R., Heathcote E.J.(1997). Combined analysis of randomized controlled trials of ursodeoxycholic acid in primary biliary cirrho-

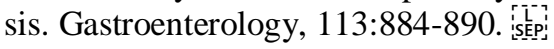

23. Corpechot, C., Carrat, F., Bahr, A., Chretien, Y., Poupon, R.E., Poupon, R.(2005). The effect of ursodeoxycholic acid therapy on the natural course of primary biliary cirrhosis. Gastroenterology, 128:297-303. [í

24. Trivedi, P.J., Lammers, W.J., van, Buuren, H.R., Pares, A., Floreani, A., Janssen, H.L. (2016). Global PBC Study Group. Stratification of hepatocellular carcinoma risk in primary biliary cirrhosis: a multi- centre international study. Gut, 65:321-329.

25. Corpechot, C., Abenavoli, L., Rabahi, N.,
Chretien, Y., Andreani, T., Johanet, C.(2008). Biochemical response to ursodeoxycholic acid and long-term prognosis in primary biliary cirrhosis. Hepatology, 48:871-877.

26. Corpechot, C., Chazouilleres, O., Poupon, R.(2011). Early primary biliary cirrhosis: biochemical response to treatment and prediction of long-term outcome. J Hepatol, 55:1361-1367. istep.

27. Carbone, M., Sharp, S.J., Flack, S., Paximadas, D., Spiess, K., Adgey, C., UK-PBC Consortium.(2016). The UK-PBC risk scores: derivation and validation of a scoring system for longterm prediction of end-stage liver disease in primary biliary cirrhosis. Hepatology, 63:930-950. SSEP'

28. Lammers, W.J., Hirschfield, G.M., Corpechot, C., Nevens, F., Lindor, K.D., Janssen H.L. (2015). Global PBC Study Group. Development and validation of a scoring system to predict outcomes of patients with primary biliary cirrhosis receiving ursodeoxycholic acid ther- apy. Gastroenterology, 149:1804-1812. icheps

29. European Association for the Study of the Liver. (2016). EASL Clinical Practice Guidelines: the diagnosis and management of patients with primary

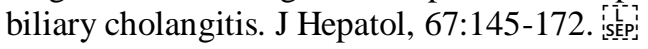

30. Lammers, W.J., Hirschfield, G.M., Corpechot, C., Nevens, F., Lindor, K.D., Janssen H.L.A.(2015). Development and Validation of a Scoring System to Predict Outcomes of Patients with Primary Biliary Cirrhosis Receiving Ursodeoxycholic Acid

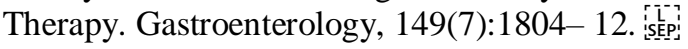

31. Akamatsu, N., Sugawara, Y. (2012). Primary biliary cirrhosis and liver transplantation. Intractable rare dis res, 1(2):66-80.

32. Raczyńska, J., Habior, A., Pączek, L., Foroncewicz, B., Pawełas, A., Mucha, K. (2014). Primary biliary cirrhosis in the era of liver transplantation. Ann transplant. 19:488-93.

33. Lee, J., Belanger, A., Doucette, J.T., Stanca, C., Friedman, S., Bach, N.(2007). Transplantation trends in primary biliary cirrhosis. Clin gastroenterol hepatol, 5(11):1313-5. 